\title{
Design of an Innovative Oxide Dispersion Strengthened AI Alloy for Selective Laser Melting to Produce Lighter Components for the Railway Sector
}

\author{
Roberto Sorci, Oriana Tassa, Alessandro Colaneri, Alessandro Astri, Daphne Mirabile, Simon Iwnicki, and Ali Gökhan Demir (D)
}

Submitted: 11 November 2020 / Revised: 11 March 2021 / Accepted: 14 March 2021 / Published online: 12 April 2021

\begin{abstract}
The railway industry can take advantage of additive manufacturing (AM) processes from several perspectives such as the production of spare parts on-demand or the use of lightweight structures for vibration and noise control. One of the key issues regarding the limitations of using these technologies is the scarcity of processable material types. Selective laser melting (SLM) is a metal AM process with industrial maturity where material development can open new prospects for the railway industry. In order to respond to such requirements, this study proposes a framework to study a new material from concept to the processability and finally to the preliminary mechanical characterization of alloy for SLM. The new material is an alloy based on AISi7Mg reinforced by alumina nano-dispersoids. The powder feedstock was produced through VIGA (Vacuum Inert Gas Atomization) technology, while the mechanical alloying of the nano-dispersoids has been carried out through the ball-milling process. The obtained oxide dispersion strengthened (ODS) powder has been used to produce samples by SLM. These samples have been characterized in terms of density, chemistry, and hardness. The obtained results showed that samples, produced by SLM were characterized by $>1 \%$ porosity. Compared to the reference $\mathrm{Al}$ alloy, an increase up to $20 \%$ in microhardness was achieved for ODS samples made by the SLM process. The results show promise especially in terms of mechanical properties, even if additional work is needed concerning both the powder production and the AM process.
\end{abstract}

Keywords additive manufacturing processes, ODS powder (oxide dispersion strengthened), SLM (selective laser melting)

\section{Introduction}

Additive manufacturing (AM) has been effectively implemented in several industries due to the geometrical freedom these processes provide to obtain new components with higher performance (Ref 1-4). The use of AM can change the logistics of production in the railway industry. The use of digital files with powder feedstock can allow for the localized production of spare parts moving away from a centralized production. The stocking of spares in warehouses can be minimized allowing for a better use of resources. The production of spare parts on demand and locally also can reduce the time to intervene with the maintenance. Another aspect regards the discontinued parts. Some older generation of vehicles may require maintenance, where the part production from scratch can be required. A digital transformation of the existing part by $3 \mathrm{D}$ scanning can

Roberto Sorci, Oriana Tassa, Alessandro Colaneri, Alessandro Astri, and Daphne Mirabile, RINA Consulting Centro Sviluppo Materiali SpA, Via di Castel Romano 100, 00128 Roma, Italy; Simon Iwnicki, Institute of Railway Research, University of Huddersfield, Queensgate, Huddersfield HD1 3DH, United Kingdom; and Ali Gökhan Demir, Department of Mechanical Engineering, Politecnico di Milano, Via La Masa 1, 20156 Milan, Italy. Contact e-mail: aligokhan.demir@polimi.it. be employed to obtain the data required for AM based production. AM also provides several possibilities for producing novel components for the railways industry. The processes can be used to effectively reduce the system complexity by reducing the number of parts to be assembled.

In the transport sector, one way to reduce fuel consumption and emissions is to reduce weight by using more lightweight materials and more efficient structural design. Lightweight materials can provide advantages also in terms of vibration control in the vehicle. Aluminium and its alloys, because of the combination of high strength, low density, corrosion resistance, and low cost, have become some of the most widely used metal materials (Ref 2). Al alloys used for AM processes are mainly based on Al-Si systems, which have limited mechanical resistance. The incorporation of nanosized ceramic reinforcements can lead to a much greater increase in the strength of $\mathrm{Al}$ alloys compared to the conventional Al-based composites.

Selective laser melting (SLM or laser powder bed fusion) is arguably the most widely used AM process in the industry for metal components. In literature, several matrix and reinforcement combinations to be used with SLM have been proposed (Ref 5-8). The material types, reinforcement size and dispersion have been the main concerns showing improvements in mechanical properties with limited process stability. It is observed that one of the main critical issues is to ensure a homogenous mixture of the starting metals and ceramic particles before SLM, which largely relies on a mechanical mixing process (e.g., ball milling). In most cases, the added fine secondary particles would deteriorate the flowability of the matrix powder (Ref 4). Moreover, due to different laser absorptivity of the ceramic particles, an apparent difference in thermal history between the ceramic particles and the metals 
would be inevitable, which can also affect or complicate the melt pool behavior. These challenges would pose significant difficulty in optimizing the SLM process of the metal matrix nano composites (MMNCs) to achieve fully dense and crackfree components.

Accordingly, this paper tackles the study of a novel powder feedstock destined to be used in railway applications. In this benchmark work, a new Al-alloy with $\mathrm{Al}_{2} \mathrm{O}_{3}$ nanoparticles to make use of the oxide dispersion strengthening (ODS) effect is produced and its processability was assessed via SLM. The paper provides the experimental details from powder manufacturing to processing and to finally evaluation of the mechanical properties as a framework to quickly assess the feasibility of using such alloys for the designated application. The alloy chosen for the preparation of the ODS powders was AlSi7Mg (A357). The alloy shows a combination of excellent castability, high strength to density ratio and corrosion resistance. Its processability via SLM has been demonstrated in several applications. The base material is a new candidate for the railways application, where steels are predominantly used for cast parts. Al-alloys are used in car body frames, while the rolling gear is composed of mainly Fe-based alloys. The inclusion of Al-alloys in the structurally critical parts requires high strength alloys. While the use of rare earths and other alloying elements can be beneficial for improved mechanical strength, the use of ceramic reinforcements is an appealing and more sustainable approach. Especially using oxide of the main alloy element $\mathrm{Al}$ is an intrinsically convenient solution concerning the material use. Hence, as the reinforcement nanometric alumina $\left(\mathrm{Al}_{2} \mathrm{O}_{3}\right)$ dispersoids was chosen. The alumina dispersoids are highly stable at high temperatures and have been used in combination with pure Al (Ref 5, 6, 9, 10), AlSi10Mg (Ref 10), pure Cu(Ref 11), and In 625 (Ref 12). A key point for the correct functioning of the SLM process with ODS powders was the size and shape stability of the powders with the correct dispersion of the reinforcement particles.

\section{Experimental Procedures}

\subsection{Alloy Selection and Fabrication of the ODS Powders}

The process steps, followed to obtain ODS powder in a pilot plant (CSM-RINA Consulting, Rome, Italy) were:

1. Preparation of master AlSi7Mg alloy ingots in vacuum induction melting (VIM) plant,

2. Production of aluminium powder in vacuum induction melting inert gas atomization (VIGA) plant,

3. Sieving of powders in the granulometric range of interest (15-65 $\mu \mathrm{m})$,

4. Production of ODS powders in a ball miller by mixing aluminium powder and alumina particles.

The nanometric-sized oxide reinforcement was dressed on the micrometer sized alloy particles as the most suitable way of providing the material preparation both in the feedstock preparation and additive manufacturing phases. Atomizing the reinforcement and the alloy together is a difficult operation as the melting temperature of $\mathrm{Al}_{2} \mathrm{O}_{3}$ is much higher than AlSi7Mg. The energy required would be much higher and a homogenous dispersion would not be possible. Instead by ball milling, the nanoparticles are placed on all the micrometric powder grains. During the SLM process, they are dispersed and mixed inside the melt pool consisting mainly of the AlSi7Mg alloy constituents. Another possibility regards the spraying of molten Al-alloy and solid ceramic nanoparticles together. This way the nanoparticles can be potentially embedded in the micro particles of the metal. However, the correct dispersion of the nanoparticles in the micrometer-sized powder as well as the control over the final nanoparticle fraction requires an indirect control through the atomization process parameters. From this point of view, ball milling was found to be a more straightforward and flexible approach.

The powder size range was chosen as 15-65 $\mu \mathrm{m}$ as commonly employed with SLM of Al-alloys (Ref 13, 14). In particular, particles smaller than $15 \mu \mathrm{m}$ cause low flowability during the process due to aggregation phenomena that obstacle the preparation of a homogeneous layer. Particles larger than 65 $\mu \mathrm{m}$ will require too high energy for local melting. The mixing stage consisted in the mixing of the AlSi7Mg powders and the $\mathrm{Al}_{2} \mathrm{O}_{3}$ nanoparticles with the aid of alumina spheres with approximately $20 \mathrm{~mm}$ diameter. At the mixing stage process parameters were studied to assess the powder quality in terms of shape, size, and dispersion of the nanoparticles. The varied parameters were the dispersion fraction, mixing time, and the sphere/powder ratio. In each experiment, 300 gr of AlSi7Mg powder was mixed with nanometre-sized $\mathrm{Al}_{2} \mathrm{O}_{3}$ particles (Baikowski, Poisy, Auvergne-Rhone-Alpes, France), characterized by a $D_{10}$ of $20 \mathrm{~nm}$ and $D_{90}$ of $40 \mathrm{~nm}$. The speed of the miller was maintained constant at $120 \mathrm{rpm}$ in an inert control volume of approximately $10 \mathrm{l}$. The ball-milling process was done in dry condition, at room temperature, without lubricant in the final powder feedstock. Eight different tests were performed as seen in Table 1 .

The chemical analysis of the AlSi7Mg alloy was performed by x-ray fluorescence on the specimen of the produced ingot and by acid attack followed by inductively coupled plasma optical emission spectroscopy (ICP-OES) analysis on the obtained powder. The reinforced powder has been observed at the SEM to qualitatively identify the distribution of the dispersoid particles.

\subsection{Production of SLM Samples}

The powder type determined in the powder production study was used for further characterization of processability by selective laser melting. A Renishaw AM250 was used throughout the experimental work (Stone, UK). The optical chain was composed of a galvanometric scanner with integrated $\mathrm{z}$-axis positioner, which enabled control of the focal position of the

Table 1 Ball-milling process parameters

\begin{tabular}{lccc}
\hline $\begin{array}{l}\text { Test } \\
\text { no }\end{array}$ & $\begin{array}{c}\text { Dispersoid } \\
\text { fraction, \%wt }\end{array}$ & $\begin{array}{c}\text { Process time, } \\
\text { min. }\end{array}$ & $\begin{array}{c}\text { Sphere/powder } \\
\text { weight ratio }\end{array}$ \\
\hline 1 & 0.5 & 30 & $1: 1$ \\
2 & 0.5 & 60 & $1: 1$ \\
3 & 0.5 & 90 & $1: 1$ \\
4 & 1.0 & 30 & $1: 1$ \\
5 & 1.0 & 60 & $1: 1$ \\
6 & 1.0 & 90 & $1: 1$ \\
7 & 1.0 & 60 & $2: 1$ \\
8 & 1.0 & 60 & $5: 1$ \\
\hline
\end{tabular}


beam. In this configuration, the estimated beam diameter is 75 $\mu \mathrm{m}$ at the focal plane. Prior to processing, vacuum is applied to the processing chamber down to - 950 mbar pressure and then was flooded with Ar reaching 15 mbar overpressure. Throughout the process, a circulation pump maintained the gas flow parallel to the powder bed and the oxygen content of the process chamber was maintained below $1000 \mathrm{ppm}$. At this initial level of the material development and processability study, it was preferred to employ small specimen geometries allowing the use a limited amount of powder feedstock. Accordingly, for new alloy development, the system is fitted with a reduced build volume (RBV) kit that allows for operating in a smaller volume $\left(78 \times 78 \times 50 \mathrm{~mm}^{3}\right)$ with a limited amount of powder.

The SLM system employed a $200 \mathrm{~W}$ single mode fiber laser modulated to PW (pulsed wave) emission. In particular, the laser emits pulses with a given power $(P)$ for a fixed pulse duration $\left(t_{\mathrm{on}}\right)$ in $\mu$ s range with a constant beam movement. The pulses are emitted between consecutive spots on the scanned line with a point distance $\left(d_{p}\right)$. At the end of each scanned line, the laser jumps to the adjacent one with a hatch distance $\left(d_{h}\right)$. The operation is continued until the layer is scanned completely. Then the whole platform is lowered by the layer thickness ( $z$ ) and a new layer of powder is deposited (Ref 15). Energy density $(E)$, an aggregate parameter commonly used in the literature to compare the processing conditions between different materials and machines, can be calculated using the following expression:

$E=\frac{\mathrm{Pt}_{\mathrm{on}}}{d_{p} d_{h} z}$

The focal position $(f)$ controls the position of the beam focal point with respect to the powder bed surface. For the present system, negative focal position values refer to a laser spot focused above the powder bed surface, and positive values refer to the focal point below the powder bed surface. In both cases, the laser beam diameter on the powder bed surface is enlarged compared to the minimum beam diameter.

A $2^{4}$ factorial design with five central points was executed producing cubic samples with $5 \mathrm{~mm}$ x $5 \mathrm{~mm}$ x $5 \mathrm{~mm}$ size. Laser power was fixed to the maximum available level. Layer thickness was fixed at $30 \mu \mathrm{m}$. Pulse duration, point distance, hatch distance and focal point were varied starting from parameters recommended for Al-alloys by the SLM machine manufacturer. Table 2 summarizes the experimental plan, while

Table 3 shows the sample number and the corresponding parameter sets.

Table 2 Fixed and variable process parameters of the experiments

Fixed process parameters

\begin{tabular}{llll}
\hline $\begin{array}{l}\text { Layer thickness, } \mathrm{z} \\
\text { Power, } \mathrm{P}\end{array}$ & $\begin{array}{l}30 \mu \mathrm{m} \\
200 \mathrm{~W}\end{array}$ & & \\
\hline Variable process parameters & Low & Mid & High \\
\hline $\begin{array}{l}\text { Pulse duration, } \mathrm{t}_{\mathrm{on}} \\
\text { Point distance, } \mathrm{d}_{\mathrm{p}}\end{array}$ & $130 \mu \mathrm{s}$ & $140 \mu \mathrm{s}$ & $150 \mu \mathrm{s}$ \\
Hatch distance, $\mathrm{d}_{\mathrm{h}}$ & $70 \mu \mathrm{m}$ & $80 \mu \mathrm{m}$ & $90 \mu \mathrm{m}$ \\
Focal point, $\mathrm{f}$ & $120 \mu \mathrm{m}$ & $130 \mu \mathrm{m}$ & $140 \mu \mathrm{m}$ \\
$1 \mathrm{~mm}$ & $2 \mathrm{~mm}$ \\
\hline
\end{tabular}

\subsection{Characterization of the SLM Samples}

After SLM, samples were cleaned and polished, following standard metallographic preparation procedures. Cross-sectional images were taken over a single cross section on the scan plane perpendicular to the build direction. The entire specimen surface was acquired and measured allowing for an acceptable measurement for the specimen density. Images of the entire samples were taken with an optical microscope (Mitutoyo Quick-Vision Active 202-Pro5f, Kanagawa, Japan). The density was measured employing image processing software by binarizing the images for revealing the pore areas as shown in Fig. 1. The apparent density $(d)$ was calculated with the following expression:

$d=\frac{A_{\text {tot }}-A_{\text {pore }}}{A_{\text {tot }}}$,

where $A_{\text {tot }}$ is the total area of the analyzed surface and $A_{\text {pore }}$ is the total pore area. Light microscopy images are commonly used in the literature as an indicator to the apparent density (Ref 16). At a level of process parameter selection, compared to other ones such as the Archimedes method and computed tomography the metallographic cross sections can provide a sufficient understanding of the densification phenomenon especially concerning the lack of fusion defects. Indeed, tomographic measurements can provide a complete view of the produced samples rather than producing several cross sections, which can provide a statistical indication.

Hardness measurement was done through indentation tests in the Vickers hardness (Future Tech, FV-700, Kawasaki, Japan). The instrument was calibrated on a $300 \mathrm{HV}$ sample with a load of $5 \mathrm{kgf}$. Energy-dispersive x-ray spectroscopy (Zeiss EDAX, Oberkochen, Germany) analyses were made using 10 $\mathrm{kV}$ voltage on the specimens within SEM (Zeiss EVO MA 15, Oberkochen, Germany) to clarify the nature of pore formation.

Table 3 List of process parameters corresponding to their sample numbers

\begin{tabular}{lcccc}
\hline Sample no & $\mathbf{t}_{\mathbf{o n}}, \boldsymbol{\mu} \mathbf{s}$ & $\mathbf{d}_{\mathbf{p}}, \boldsymbol{\mu} \mathbf{m}$ & $\mathbf{d}_{\mathbf{h}}, \boldsymbol{\mu} \mathbf{m}$ & $\mathbf{f}, \mathbf{m m}$ \\
\hline 1 & 150 & 70 & 140 & 0 \\
2 & 130 & 90 & 120 & 0 \\
3 & 150 & 70 & 120 & 0 \\
4 & 130 & 90 & 140 & 2 \\
5 & 130 & 70 & 140 & 2 \\
6 & 140 & 80 & 130 & 1 \\
7 & 150 & 90 & 120 & 0 \\
8 & 150 & 70 & 120 & 2 \\
9 & 140 & 80 & 130 & 1 \\
10 & 130 & 90 & 140 & 0 \\
11 & 130 & 70 & 120 & 2 \\
12 & 140 & 80 & 130 & 1 \\
13 & 150 & 70 & 140 & 2 \\
14 & 130 & 70 & 120 & 0 \\
15 & 130 & 90 & 120 & 2 \\
16 & 150 & 90 & 140 & 0 \\
17 & 140 & 80 & 130 & 1 \\
18 & 150 & 90 & 140 & 2 \\
19 & 150 & 90 & 120 & 2 \\
20 & 130 & 70 & 140 & 0 \\
21 & 140 & 80 & 130 & 1 \\
\hline
\end{tabular}



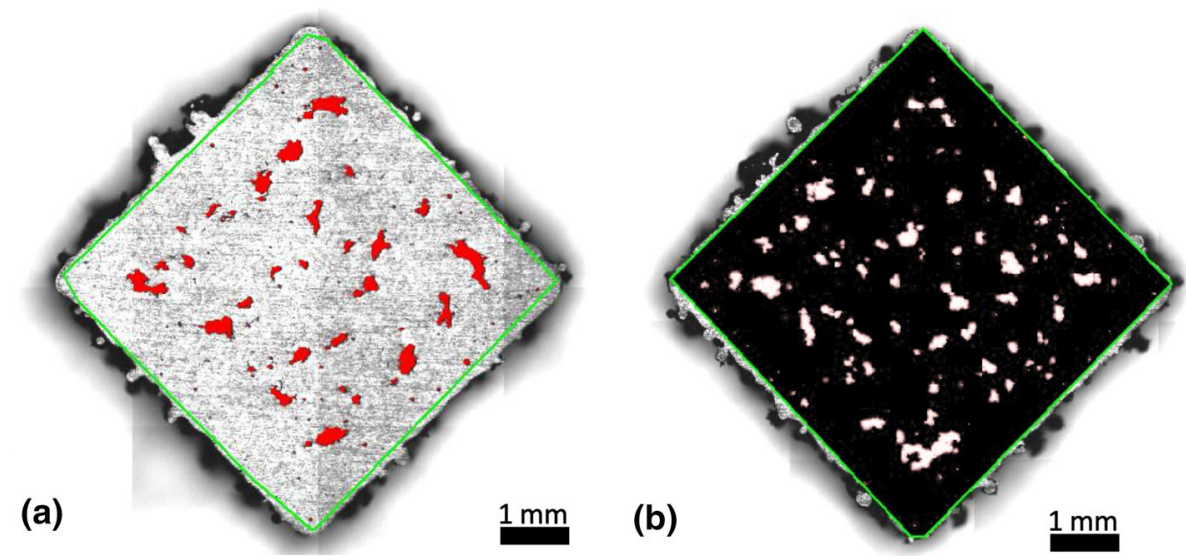

Fig. 1 Density measurement procedure via the optical microscopy images showing the image binarization and the revealing of the pores. (a) Initial image with pores and (b) image after binarization with pores highlighted in white (Color figure online)

Table 4 Chemical composition of the nominal and produced powder prior to ball milling

\begin{tabular}{lllrrrr}
\hline Element & $\mathbf{S i}$ & $\mathbf{M g}$ & $\mathbf{F e}$ & Mn & Cu & Al wt.\% \\
\hline Nominal wt.\% & $6.5-7.5$ & $0.40-0.70$ & $<0.20$ & $<0.10$ & $<0.20$ & bal. \\
Measured wt.\% & 7.0 & 0.40 & 0.35 & 0.30 & 0.10 & bal \\
\hline
\end{tabular}

\section{Results}

\subsection{Powder Production}

The powder feedstock produced had the chemical composition shown in Table 4 prior to ball milling. The alloying elements were found to be within the range. Some of the impurities were higher than the nominal (Fe and $\mathrm{Mn}$ ). In the first three ball milling tests, where the process time was varied with a dispersion fraction of $0.5 \mathrm{wt} . \%$, no satisfactory results were obtained in terms of imprinting. Moreover, some aluminium particles were deformed in the third test (see test 3 in Fig. 2). In tests 3 to 6 , the dispersoid weight fraction was increased to $1 \mathrm{wt} . \%$ and the process time was modulated, as in the previous trials. With $1 \mathrm{w} \%$ dispersoid fraction and high process duration powder particles were deformed in test 6 . Considering the results obtained, the test 7 was performed by fixing the process time $(60 \mathrm{~min})$ and the dispersoid level at 1 wt.\% while increasing the sphere/powder weight ratio to $2: 1$. A considerable increase in the alumina particles embedded on the AlSi7Mg powder could be obtained. Finally, in test 8 the sphere/powder weight ratio was further increased to $5: 1$. However, a large fraction of particles lost their sphericity (test 8 in Fig. 2). The best result in terms of alumina particle coating was therefore obtained in the test 7 . The final particle size distribution was in the desired range with $\mathrm{D}_{10}=14.7 \mu \mathrm{m}, \mathrm{D}_{50}=$ $31.6 \mu \mathrm{m}$ and $\mathrm{D}_{90}=61.5 \mu \mathrm{m}$. As seen in the SEM images in Fig. 2, the test 7 condition provided also a good distribution of the oxide nanoparticles as a dressing on the micrometric Alalloy particles without agglomerations or clusters. This condition was chosen to produce the ODS powder to be processed by SLM.

\subsection{Density of SLM Produced Specimens}

AlSi7Mg powder with 1 wt. $\% \mathrm{Al}_{2} \mathrm{O}_{3}$ nano-dispersoids was processed via SLM. Figure 3 shows the produced specimens on the build plate. The visual inspections show the specimens are characterized by a high level of surface irregularities. Such conditions can be linked to a high degree of shrinkage and balling phenomenon. In particular, balling phenomenon forms when the melt pool begins to detach to form droplets of discontinuous metal (Ref 17-19). One of the causes for balling is the low wettability of the molten metal to the surrounding solid (Ref 20). The presence of ODS particles can induce such phenomenon (Ref 10, 21).

Figure 4(a) shows the measured density values of each sample. Figure 4(b) depicts the main effects of the process parameters and Fig. 4(c) the dependence on energy density. The overall results showed that the specimens were characterized by a high amount of porosity, while the results varied between 94 and $99 \%$. For industrial use, the expected part density should preferably exceed $99 \%$. As seen in Fig. 4(b), the strongest parameter appears as the point distance $\left(d_{p}\right)$. Through the analysis of variance (ANOVA), it was seen that the only significant parameter controlling the part density was the point distance $\left(d_{p}\right)$ with a statistical significance level at $\alpha=5 \%$. The details of ANOVA are shown in Table 5. A reduction of point distance showed an improvement in the part density from approximately $96 \%$ to approximately $98 \%$. The reduction of point distance corresponds to a more pronounced thermal field along the scanned line allowing to increase the temperature locally. This is expected to reduce the effect of balling by maintaining a higher temperature and improve the wetting behavior. Moreover, it was observed that the energy density does not fully describe the densification of the material as denoted by a large dispersion of the density values with respect to the overall trend as seen in Fig. 4(c). 


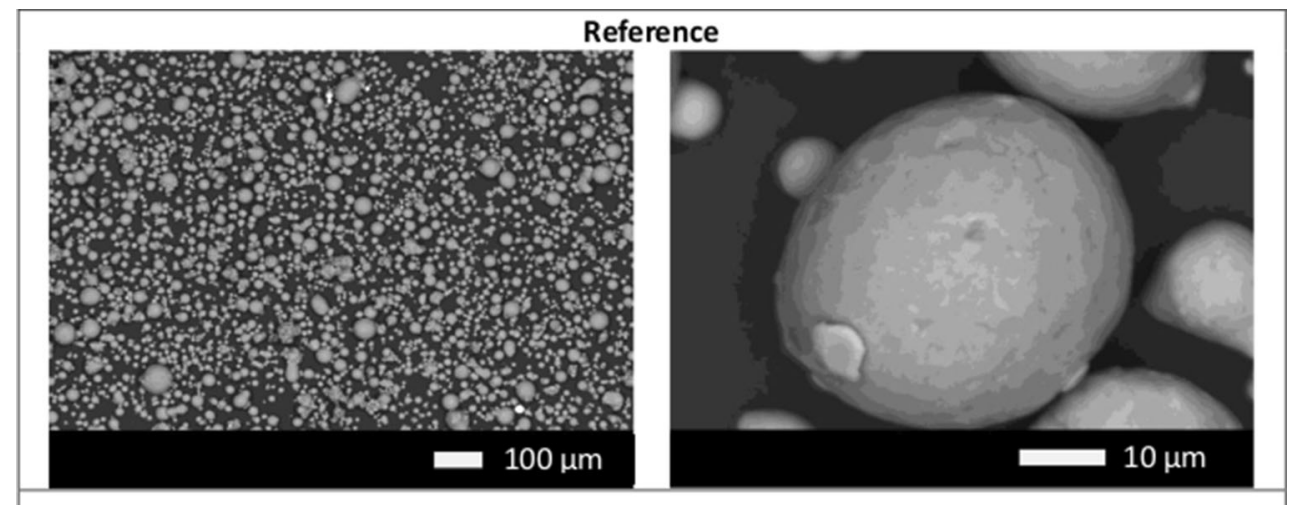

Test 3

Disperoid fraction $0.5 \mathrm{wt} \%$, process time $90 \mathrm{~min}$, sphere/powder weight ratio 1:1

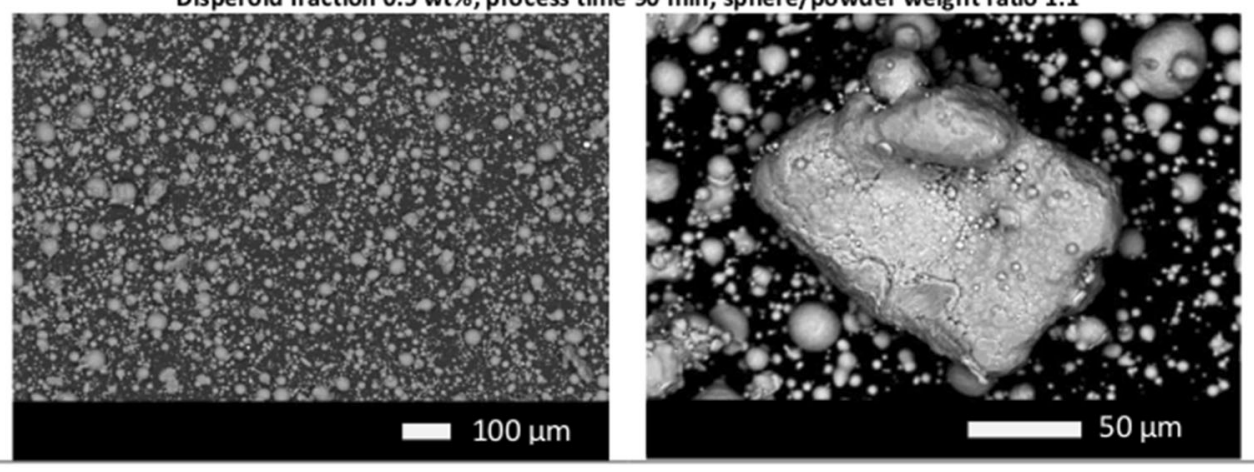

Test 7

Disperoid fraction $1.0 \mathrm{wt} \%$, process time $60 \mathrm{~min}$, sphere/powder weight ratio $1: 1$

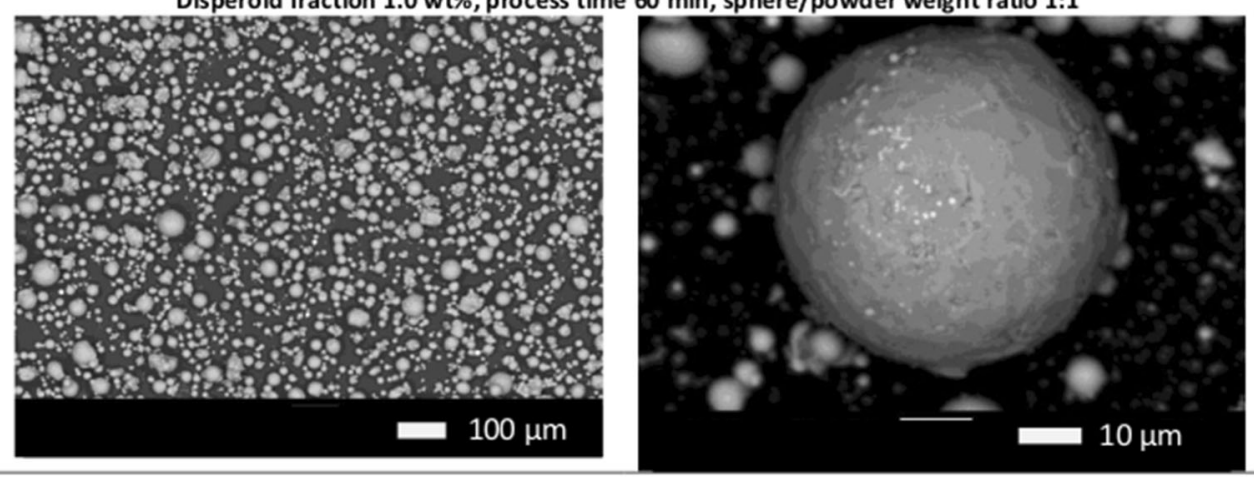

Test 8

Disperoid fraction $1.0 \mathrm{wt} \%$, process time $60 \mathrm{~min}$, sphere/powder weight ratio 5:1

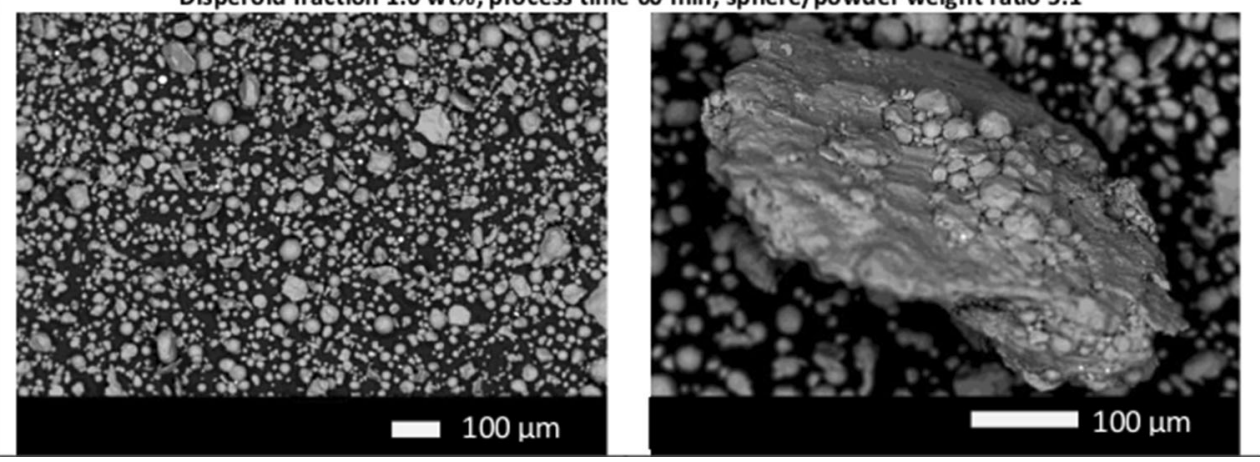

Fig. 2 SEM images of example test cases of ODS powders. For the details of the test conditions, refer to Table 1 


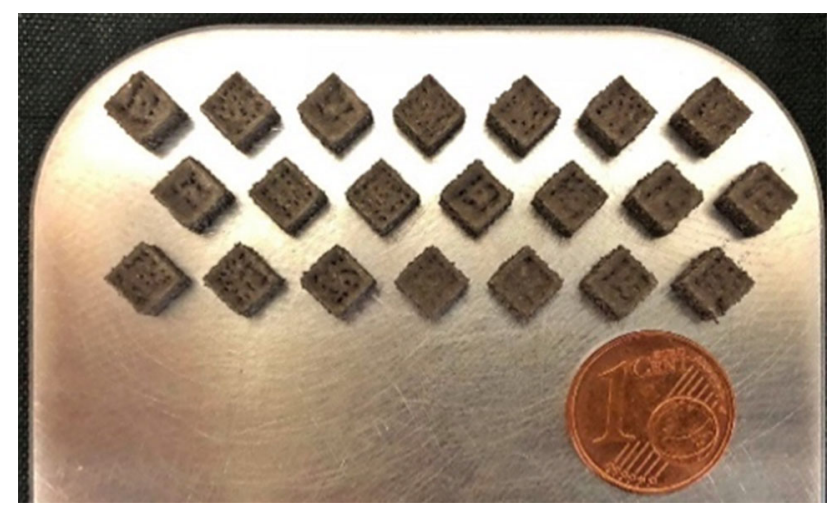

Fig. 3 Macro images of the samples after SLM

Based on the density data, samples 1, 2, 13, 17, 18, characterized by maximum, minimum, and intermediate values, have been chosen for further characterization tests (filled bars in Fig. 4a). The samples were cut perpendicularly to the build direction for metallographic characterizations. The optical microscope image analysis showed pores, but no cracks caused were observed. These pores were observed to be caused by unmelted particles. Samples 1, 2, and 18 presented large pores extending along different layers (Fig. 5). The most homogeneous structure has been observed in case samples 13 and 17. The presence of unmelted regions can be attributed to the lack of fusion in a first attempt (Ref 22). However, the employed energy density range is large and encompasses between $70 \mathrm{~J} /$ $\mathrm{mm}^{3}$ and $120 \mathrm{~J} / \mathrm{mm}^{3}$. The energy density range is also high for the conventional AlSi7Mg alloy processed by SLM. For instance Grande et al (Ref 14) employed $93 \mathrm{~J} / \mathrm{mm}^{3}$ for high density parts in AlSi7Mg. Kimura and Nakamoto achieved high density parts at approximately $60 \mathrm{~J} / \mathrm{mm}^{3}$ and observed density reduction above $100 \mathrm{~J} / \mathrm{mm}^{3}$ with the same alloy (Ref 13). Moreover, the defects are found to be large, propagating along several layers indicating that the lack of fusion is not likely to be the main cause. It is expected that the balling phenomenon caused by the low wettability of the alumina can be the main issue.

Figure 6 shows the EDS analysis on the darker regions in the vicinity of a large pore (all spectra indicate dark regions excluding the bulk material). EDS investigations showed a high percentage of aluminium and oxygen at close proximity of the pore, while the rest of the metal matrix was composed by aluminium, silicon, and magnesium. Based on this observation the porosity could be caused by aggregation of nano-dispersoids of alumina during the ball-milling process further reducing the wettability of the liquid $\mathrm{Al}$ on this aggregation zone.

\subsection{Mechanical Properties}

Vickers microhardness values measured on the representative samples and compared to the SLM produced AlSi7Mg without disperoids are shown in Fig. 7. Hardness values are very similar to the ones obtained in the case of SLM sample prepared with commercial AlSi7Mg powder. This result can be associated to the porosity rather than the lack of reinforcement. To confirm this hypothesis, microhardness measurements were carried out in different areas of the samples, close to and far from a porosity zone. For each sample, three measurements were performed.
Mircohardness measurements carried out around the vicinity of the pores and in the fully dense zones can be seen in Fig. 8. A remarkable reduction of hardness is observed due to voids around the pores. Instead on the fully dense regions, the microhardness values were significantly higher than the reference of AlSi7Mg with an increase of up $20 \%$.

\section{Discussion}

The employed experimental design provides further insights to the pore formation mechanisms. The experiments follow a full factorial design, randomization on the baseplate and replication in the central point clearing out the systematic influence of disturbance factors. Some of these factors are local agglomeration of the reinforcing particles and inconstant powder bed compaction level. The results of ANOVA allow to indicate the statistically significant process parameters by also providing the means to limit the influence of uncontrolled factors. The analysis on the residuals in terms of homogeneity and independence, which are not reported here for brevity confirm the absence of a systematic error influence. Under the light of these observations, it can be hypothesized that the pore formation mechanism and the relatively large variability observed in the central point are linked to the melting dynamics of the specific powder. Hence, the pore formation mechanism based on scarce wettability caused by an unideal dispersion of the nano-dispersoids is strengthened.

The results obtained in this work give a clear indication that the alumina particle dispersion affects the material properties. The distribution of oxide particles is not yet optimized, producing clusters that affect porosity and, therefore, the laser workability. Where fine and homogeneous dispersion was present, uniform zones are evident, and microhardness measurement has demonstrated significant improvement respect to the alloy without dispersoids. In fact, the finer the dispersoids are, the lower is the distance between particles, the greater the effect on mechanical resistance. The size and fraction of $\mathrm{Al}_{2} \mathrm{O}_{3}$ nanoparticles can be optimized to achieve higher mechanical strength, according to Ashby-Orowan model (Ref 23). The model describes the increase in the yield strength $\sigma_{\text {ppt }}$ with the following expression:

$\sigma_{\mathrm{ppt}}=0.84 \cdot \frac{1.2 M \mu b}{2 \pi \lambda_{p}} \ln \left(\frac{\sqrt{2 / 3} r_{p}}{2 b}\right)$

, where $M$ is Taylor factor (3.06 for FCC materials), $\mu$ is the shear modulus (28 GPa), $b$ is burger vector $(0.25 \mathrm{~nm}), \lambda_{p}$ is the mean distance between particles, $r_{p}$ is the average particle radius. The interparticle spacing $\lambda_{p}$ can be estimated with the expression:

$\lambda_{p}=r_{p} \sqrt{\frac{2 \pi}{3 f_{r}}}$

, where $f_{r}$ is the volume fraction of particles. According to Eqs. 3 and 4, an increase of the alloy strength of about $50 \mathrm{MPa}$ and $35 \mathrm{MPa}$ is expected respectively for a particle fraction of $1 \%$ and $0.5 \%$, considering an average particle diameter of $30 \mathrm{~nm}$. This result is in line with the obtained results in terms of microhardness. 
(a)
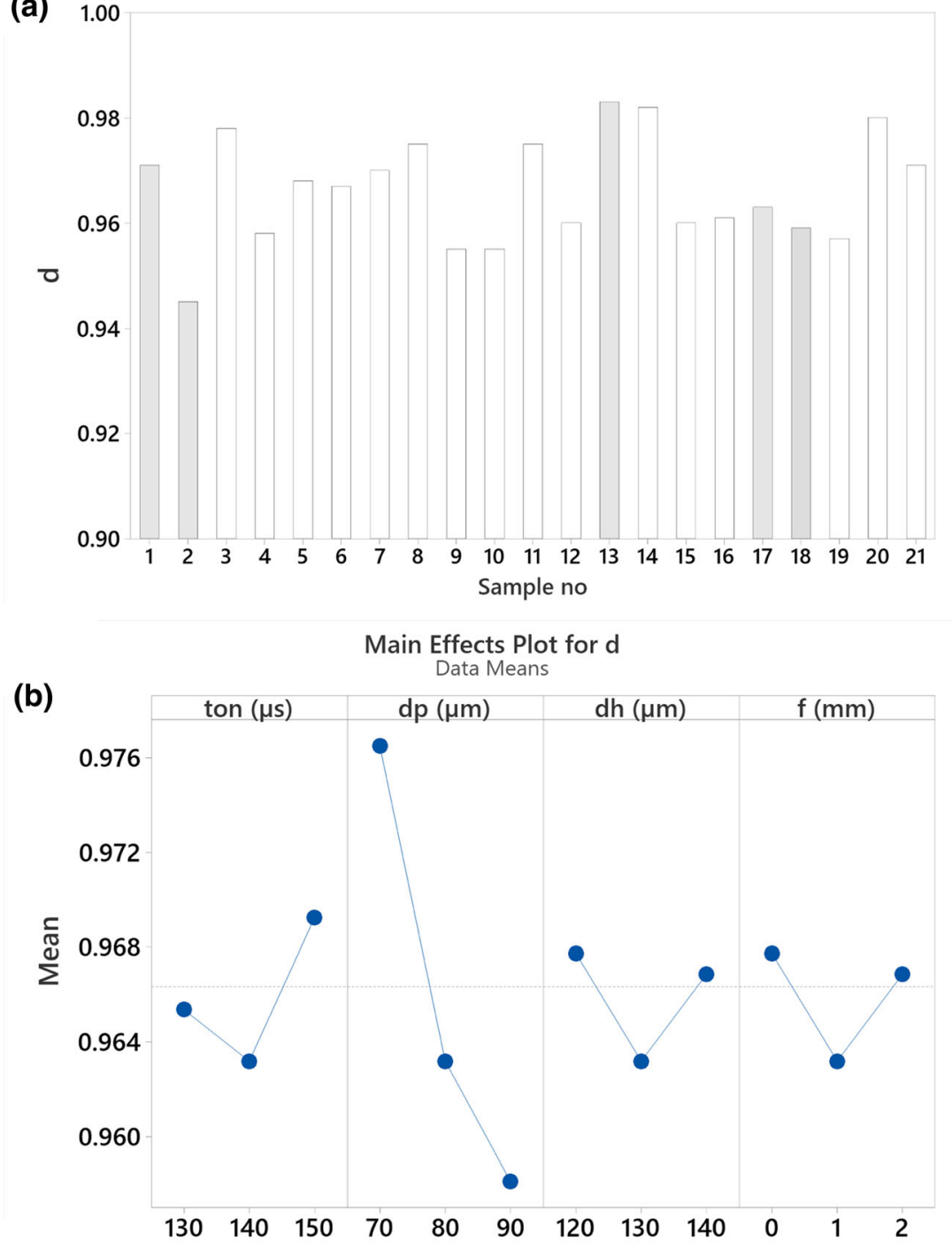

(c) 1.00

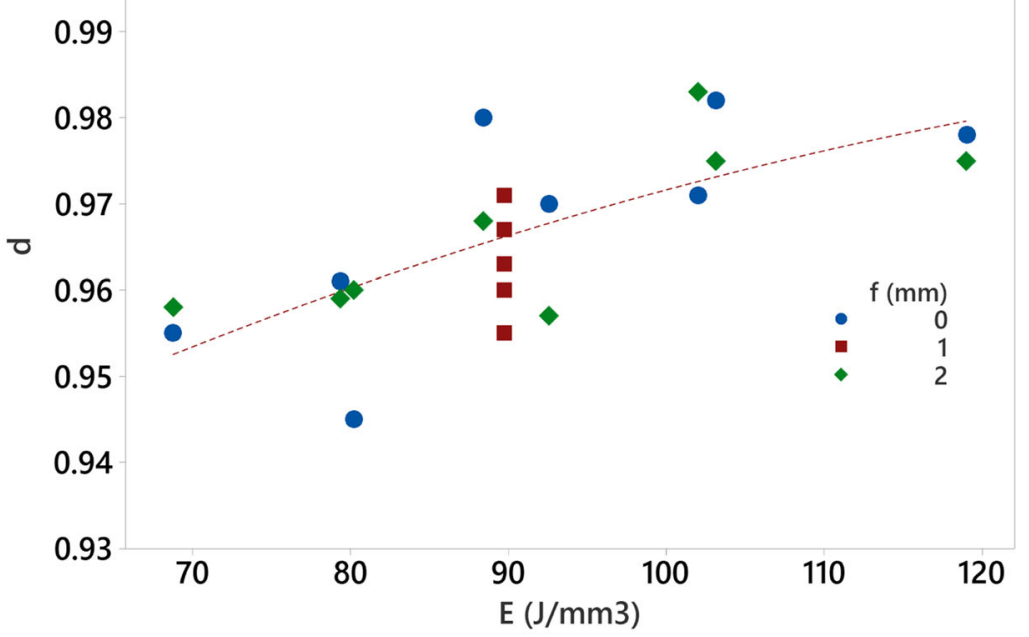

Fig. 4 (a) Measured density values of each sample (filled bars indicate selected conditions for further analysis), (b) main effects of the process parameters, and (c) the density variation against the energy density (the dashed line indicates trend only) 
Table 5 Analysis of variance (ANOVA) table for density (d). The statistically significant factor is shown in bold

\begin{tabular}{|c|c|c|c|c|c|}
\hline Term & Effect & Coef & SE Coef & $T$-value & $P$-value \\
\hline Constant & & 0.96731 & 0.00155 & 626.03 & 0.000 \\
\hline$t_{\mathrm{on}}, \mu \mathrm{s}$ & 0.00388 & 0.00194 & 0.00155 & 1.25 & 0.278 \\
\hline $\mathrm{d}_{\mathrm{p}}, \mu \mathrm{m}$ & -0.01838 & -0.00919 & 0.00155 & -5.95 & 0.004 \\
\hline $\mathrm{d}_{\mathrm{h}}, \mu \mathrm{m}$ & -0.00088 & -0.00044 & 0.00155 & -0.28 & 0.791 \\
\hline $\mathrm{F}, \mathrm{mm}$ & -0.00088 & -0.00044 & 0.00155 & -0.28 & 0.791 \\
\hline $\mathrm{t}_{\mathrm{on}}, \mu \mathrm{s}^{*} \mathrm{~d}_{\mathrm{p}}, \mu \mathrm{m}$ & 0.00338 & 0.00169 & 0.00155 & 1.09 & 0.336 \\
\hline $\mathrm{t}_{\mathrm{on}}, \mu \mathrm{s}^{*} \mathrm{~d}_{\mathrm{h}}, \mu \mathrm{m}$ & -0.00063 & -0.00031 & 0.00155 & -0.20 & 0.850 \\
\hline $\mathrm{t}_{\mathrm{on}}, \mu \mathrm{s} * \mathrm{f}, \mathrm{mm}$ & -0.00062 & -0.00031 & 0.00155 & -0.20 & 0.850 \\
\hline $\mathrm{d}_{\mathrm{p}}, \mu \mathrm{m} * \mathrm{~d}_{\mathrm{h}}, \mu \mathrm{m}$ & 0.00113 & 0.00056 & 0.00155 & 0.36 & 0.734 \\
\hline $\mathrm{d}_{\mathrm{p}}, \mu \mathrm{m} * \mathrm{f}, \mathrm{mm}$ & 0.00163 & 0.00081 & 0.00155 & 0.53 & 0.627 \\
\hline $\mathrm{d}_{\mathrm{h}}, \mu \mathrm{m}^{*} \mathrm{f}, \mathrm{mm}$ & 0.00113 & 0.00056 & 0.00155 & 0.36 & 0.734 \\
\hline $\mathrm{t}_{\mathrm{on}}, \mu \mathrm{s}^{*} \mathrm{~d}_{\mathrm{p}}, \mathrm{um} \mu \mathrm{m} \mathrm{d}_{\mathrm{h}}, \mu \mathrm{m}$ & -0.00313 & -0.00156 & 0.00155 & -1.01 & 0.369 \\
\hline $\mathrm{t}_{\mathrm{on}}, \mu \mathrm{s} * \mathrm{~d}_{\mathrm{p}}, \mu \mathrm{m} * \mathrm{f}, \mathrm{mm}$ & -0.00763 & -0.00381 & 0.00155 & -2.47 & 0.069 \\
\hline $\mathrm{t}_{\mathrm{on}}, \mu \mathrm{s} * \mathrm{~d}_{\mathrm{h}}, \mu \mathrm{m} * \mathrm{f}, \mathrm{mm}$ & 0.00538 & 0.00269 & 0.00155 & 1.74 & 0.157 \\
\hline $\mathrm{d}_{\mathrm{p}}, \mu \mathrm{m} * \mathrm{~d}_{\mathrm{h}}, \mu \mathrm{m} * \mathrm{f}, \mathrm{mm}$ & -0.00138 & -0.00069 & 0.00155 & -0.44 & 0.679 \\
\hline $\mathrm{t}_{\mathrm{on}}, \mu \mathrm{s} * \mathrm{~d}_{\mathrm{p}}, \mu \mathrm{m} * \mathrm{~d}_{\mathrm{h}}, \mu \mathrm{m} * \mathrm{f}, \mathrm{mm}$ & 0.00037 & 0.00019 & 0.00155 & 0.12 & 0.909 \\
\hline Centre point & & -0.00411 & 0.00317 & -1.30 & 0.264 \\
\hline
\end{tabular}

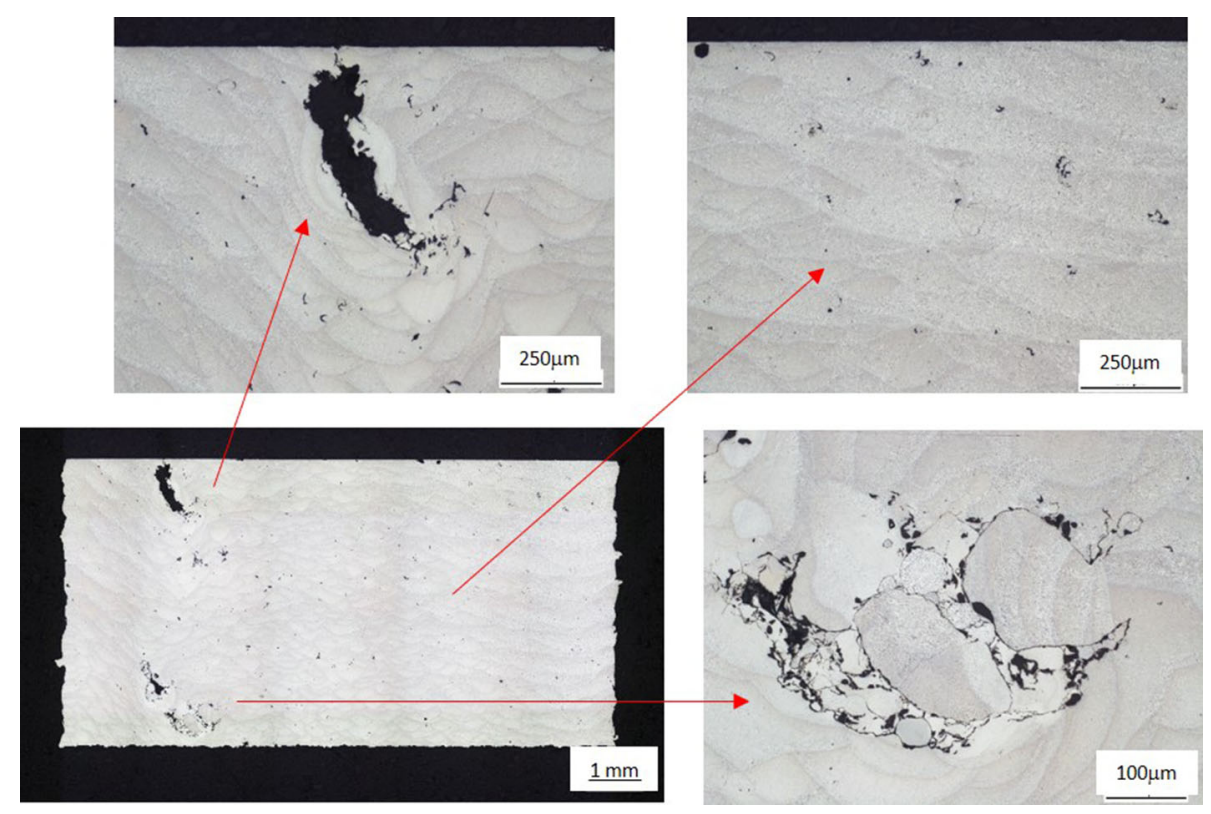

Fig. 5 Example of different pore types seen in sample $n^{\circ} 1$. Build direction follows the vertical axis of the images

Such an increment in the mechanical strength can be highly beneficial for the Al-alloys. Concerning the conventional AlSi7Mg produced by casting the yield strength is approximately $120 \mathrm{MPa}$, which can be improved by a T6 heat treatment to approximately 270-300 MPa (Ref 24). As-built yield strength of SLM produced AlSi7Mg is approximately 275-310 MPa (Ref 25, 26), which is similar to the cast alloy after a dedicated aging treatment. Concerning a first approximation, the addition of nanoparticles can provide up to $18 \%$ increase (50 MPa increase over $275 \mathrm{MPa}$ ) in the yield strength on the SLM produced AlSi7Mg in as-built conditions. In order to reach the final application requirements of the railways industry, the ball-milling process should be better managed for a more homogenous dispersion. This would improve the processability potentially. Powder bed preheating can also provide improved results by enhancing the wettability of the material. However, the final mechanical properties are expected to be altered due to the different cooling rates. Another open point regards the tailoring of the heat treatments after SLM, in order to further enhance the mechanical properties.

The issue of porosity could be potentially resolved via hot isostatic pressing (HIP). The feasibility of using HIP for the closure of SLM produced AlSi10Mg has been shown (Ref 27). While the pores appeared to be closed a significant reduction in the mechanical behavior was observed, since the process acted as a heat treatment significantly altering the material microstructure. The use of HIP on electron beam melted (EBM) alloys has been proven to be highly beneficial to close the pores and improve the mechanical properties (Ref 28). However, the EBM process works under vacuum. The SLM process was carried out under Ar atmosphere. Hence, the pores are expected to be filled with Ar by the end of their formation. 


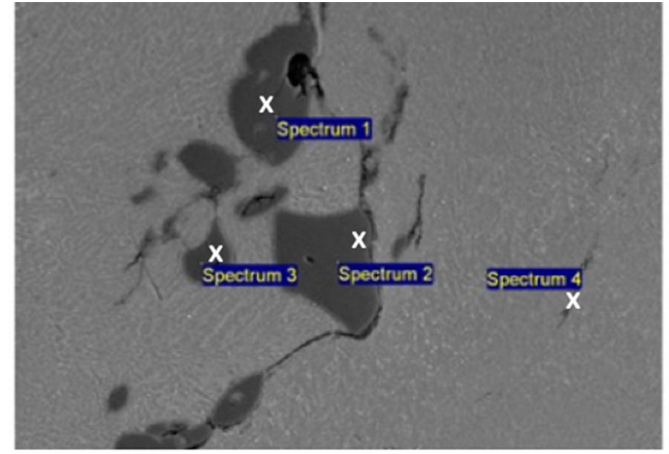

$40 \mu \mathrm{m}$

$10 \mathrm{kV}$

\begin{tabular}{|c|c|c|c|c|c|}
\hline Spectrum & $O$ & $\mathrm{Mg}$ & $\mathrm{Al}$ & $\mathrm{Si}$ & Total \\
\hline Spectrum 1 & 49.06 & 0.78 & 50.16 & & 100.00 \\
\hline Spectrum 2 & 49.65 & & 50.35 & & 100.00 \\
\hline Spectrum 3 & 49.77 & 2.31 & 47.92 & & 100.00 \\
\hline Spectrum 4 & 6.07 & & 84.14 & 9.79 & 100.00 \\
\hline
\end{tabular}

Fig. 6 SEM-EDS analysis close to a formed pore. The chemical analysis measurements are given in wt.\%

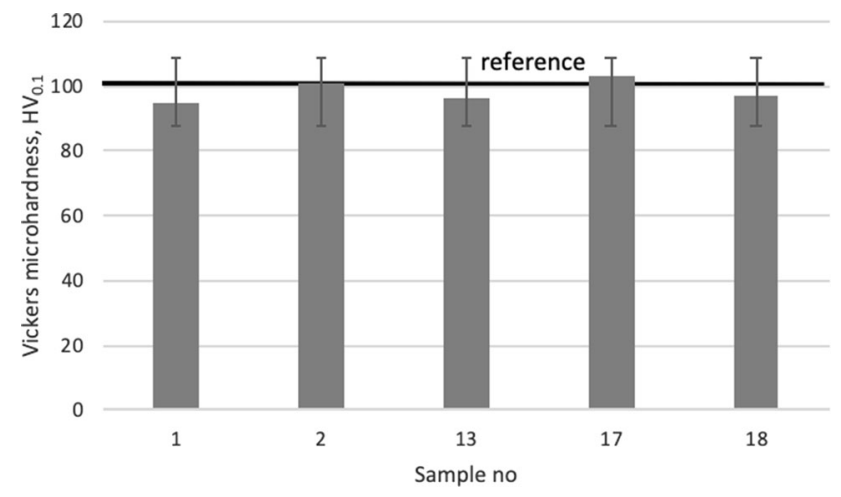

Fig. 7 Average Vickers microhardness of the selected conditions

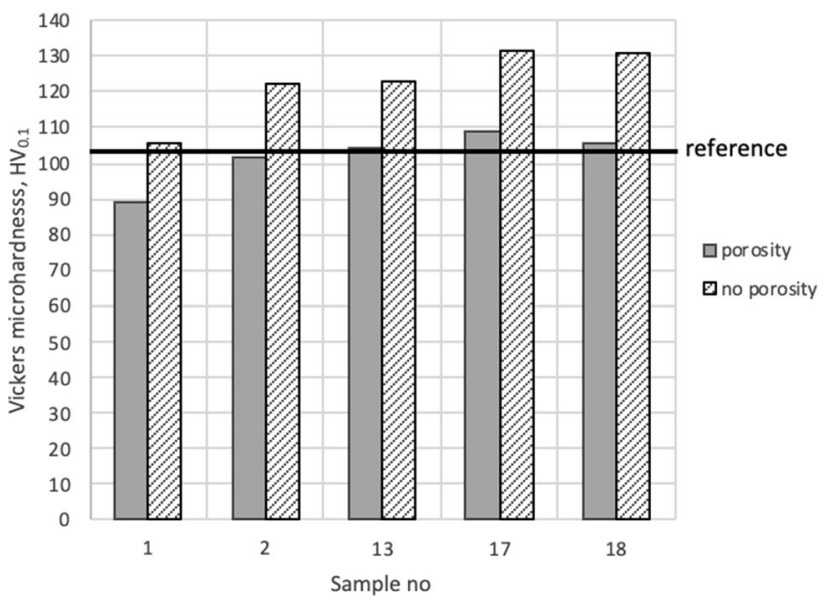

Fig. 8 Microhardness of the sample close to (grey bars) and far (hatched bars) from the porosity zone (Color figure online)

The use of HIP can compress the pores and the gas within them, while the complete closure of the pores may not be achieved (Ref 29). Hence, the static and fatigue properties can only be improved to a limited degree.
Within this work, small cubic samples were used in order to assess the processability of the newly developed powder feedstock. The scalability of the process to larger components with adequate mechanical properties required for railways should be further investigated. The study on scan strategies allowing to distribute the energy input more homogenously on larger areas should be carried out in future works. For larger parts baseplate preheating can provide a reduction of the thermal distortions common to the SLM processed Al-alloys (Ref 30).

\section{Conclusions}

In this work, a new aluminium alloy powder reinforced by alumina dispersoids has been designed, produced, and used for the preparation of samples by SLM with the aim to use this new material for railway applications. The main outcomes of the work can be summarized as the following.

- The AlSi7Mg base powder has been produced through VIGA technology. The ball-milling process was successfully employed to dress the micrometric powders with nanometric $\mathrm{Al}_{2} \mathrm{O}_{3}$ particles. SLM technique was used to produce samples with the obtained ODS powder.

- SLM of the newly developed AlSi7Mg + $1 \mathrm{wt} . \% \mathrm{Al}_{2} \mathrm{O}_{3}$ powder showed an average value of about $2 \%$ porosity. Although the significant amount of porosity, the samples were crack free.

- The pores in the SLM produce samples were mainly caused by the balling phenomenon. SEM-EDS analysis showed high percentage of aluminium and oxygen at close proximity of a pores. The aggregation of nano-dispersoids of alumina during the ball-milling process can cause oxide accumulation generating balling and an unstable SLM process.

- Microhardness of the SLM produced AlSi7Mg + 1wt.\% $\mathrm{Al}_{2} \mathrm{O}_{3}$ samples were close to the non-reinforced $\mathrm{AlSi} 7 \mathrm{Mg}$ processed by SLM. This was due to the interplay between harder reinforced zones along with softer zones around the pores.

In addition to the observed results, here a framework of material development from powder production to SLM processing was assessed. Indeed, as a main conclusion, it is observed that the approach may require several iterations between the different phases. In this case, further studies are necessary to improve alumina dispersion and particles dimension and sphericity during mechanical alloying.

\section{Acknowledgments}

The work described in the present paper was developed within the project entitled "Innovative RUNning gear soluTiOns for new dependable, sustainable, intelligent and comfortable RAIL vehicles" (RUN2Rail) and has received funding from the European Union's Horizon 2020 research and innovation program under Grant Agreement No 777564. The European Union's Horizon 2020 research and innovation program is gratefully acknowledged. The Union is not responsible for any use that may be made of the information contained therein. 


\section{Funding}

Open access funding provided by Politecnico di Milano within the CRUI-CARE Agreement.

Open Access This article is licensed under a Creative Commons Attribution 4.0 International License, which permits use, sharing, adaptation, distribution and reproduction in any medium or format, as long as you give appropriate credit to the original author(s) and the source, provide a link to the Creative Commons licence, and indicate if changes were made. The images or other third party material in this article are included in the article's Creative Commons licence, unless indicated otherwise in a credit line to the material. If material is not included in the article's Creative Commons licence and your intended use is not permitted by statutory regulation or exceeds the permitted use, you will need to obtain permission directly from the copyright holder. To view a copy of this licence, visit http://creativecommons.org/licenses/by/4.0/.

\section{References}

1. N.T. Aboulkhair, M. Simonelli, L. Parry, I. Ashcroft, C. Tuck and R. Hague, 3D Printing of Aluminium alloys: Additive Manufacturing of Aluminium alloys using Selective Laser Melting, Prog. Mater. Sci., 2019, 106, p 100578. https://doi.org/10.1016/j.pmatsci.2019.100578

2. M. Wang, B. Song, Q. Wei, Y. Zhang and Y. Shi, Effects of Annealing on the Microstructure and Mechanical Properties of Selective Laser Melted AlSi7Mg Alloy, Mater. Sci. Eng. A., 2019, 739, p 463-472. h ttps://doi.org/10.1016/j.msea.2018.10.047

3. J.M. Benson and E. Snyders, The Need for Powder Characterisation in the Additive Manufacturing, South African J. Ind. Eng., 2015, 26, p 104-114

4. M. Yakout, M.A. Elbestawi and S.C. Veldhuis, A Review of Metal Additive Manufacturing Technologies, Solid State Phenom., 2018, 278, p 1-14. https://doi.org/10.4028/www.scientific.net/SSP.278.1

5. Q. Han, R. Setchi, F. Lacan, D. Gu and S.L. Evans, Selective Laser Melting of Advanced Al-Al2O3 Nanocomposites: Simulation, Microstructure and Mechanical Properties, Mater. Sci. Eng. A., 2017, 698, p 162-173. https://doi.org/10.1016/j.msea.2017.05.061

6. J. Jue, D. Gu, K. Chang and D. Dai, Microstructure Evolution and Mechanical Properties of Al-A12O3 Composites Fabricated by Selective Laser Melting, Powder Technol., 2017, 310, p 80-91. https://doi. org/10.1016/j.powtec.2016.12.079

7. D. Gu, H. Wang, F. Chang, D. Dai, P. Yuan, Y.C. Hagedorn and W. Meiners, Selective Laser Melting Additive Manufacturing of TiC/ AlSi10Mg Bulk-Form Nanocomposites with Tailored Microstructures and Properties, Phys. Procedia., 2014, 56, p 108-116. https://doi.org/ 10.1016/j.phpro.2014.08.153

8. Q. Han, Y. Geng, R. Setchi, F. Lacan, D. Gu and S.L. Evans, Macro and Nanoscale Wear Behaviour of Al-A12O3 Nanocomposites Fabricated By Selective Laser Melting, Compos. Part B Eng., 2017, 127, p 26-35. https://doi.org/10.1016/j.compositesb.2017.06.026

9. Q. Han, Y. Geng, R. Setchi, F. Lacan, D. Gu and S.L. Evans, Macro and Nanoscale Wear Behaviour of Al-A12O3nanocomposites Fabricated by Selective Laser Melting, Compos. Part B Eng., 2017, 127, p 26-35. https://doi.org/10.1016/j.compositesb.2017.06.026

10. L. Wang, J. Jue, M. Xia, L. Guo, B. Yan and D. Gu, Effect of the Thermodynamic Behavior of Selective Laser Melting on the Formation of In situ Oxide Dispersion-Strengthened Aluminum-Based Composites, Metals (Basel), 2016, 6, p 286. https://doi.org/10.3390/met61102 86

11. M.A. Lodes, C. Koerner and C.R. Pobel, Selective Electron Beam Melting of Oxide Dispersion Strengthened Copper, Adv. Eng. Mater, 2018, 1800068, p 1-7. https://doi.org/10.1002/adem.201800068
12. D.E. Cooper, N. Blundell, S. Maggs and G.J. Gibbons, Additive Layer Manufacture of Inconel 625 Metal Matrix Composites, Reinforcement Material Evaluation, J. Mater. Process. Technol., 2013, 213, p 21912200. https://doi.org/10.1016/j.jmatprotec.2013.06.021

13. T. Kimura and T. Nakamoto, Microstructures and Mechanical Properties of A356 (AlSi7Mg0.3) Aluminum Alloy Fabricated by Selective Laser Melting, Mater. Des., 2016, 89, p 1294-1301. https://doi.org/10. 1016/j.matdes.2015.10.065

14. AM. Grande, S. Cacace, AG. Demir and G Sala, Fracture and fatigue behaviour of AlSi7Mg0. 6 produced by Selective Laser Melting: effects of thermal-treatments, 25th Conf. Ital. Assoc. Aeronaut. Astronaut. (AIDAA 2019). (2019) 1138-1144

15. A.G. Demir, P. Colombo and B. Previtali, From Pulsed to Continuous Wave Emission in SLM with Contemporary Fiber Laser Sources: Effect of Temporal and Spatial Pulse Overlap in Part Quality, Int. J. Adv. Manuf. Technol., 2017, 91, p 2701-2714. https://doi.org/10.1007/ s00170-016-9948-7

16. A.B. Spierings, M. Schneider and R. Eggenberger, Comparison of Density Measurement Techniques for Additive Manufactured Metallic Parts, Rapid Prototyp. J., 2011, 17, p 380-386. https://doi.org/10.1108/ 13552541111156504

17. J.P. Kruth, L. Froyen, J. Van Vaerenbergh, P. Mercelis, M. Rombouts and B. Lauwers, Selective Laser Melting of Iron-Based Powder, J. Mater. Process. Technol., 2004, 149, p 616-622. https://doi.org/10. 1016/j.jmatprotec.2003.11.051

18. I. Yadroitsev, P. Krakhmalev, I. Yadroitsava, S. Johansson and I. Smurov, Energy Input Effect on Morphology and Microstructure of Selective Laser Melting Single Track from Metallic Powder, J. Mater. Process. Technol., 2013, 213, p 606-613. https://doi.org/10.1016/j.jma tprotec.2012.11.014

19. K. Mumtaz and N. Hopkinson, Top Surface and Side Roughness of Inconel 625 Parts Processed Using Selective Laser Melting, Rapid Prototyp. J., 2009, 15, p 96-103. https://doi.org/10.1108/1355254091 0943397

20. C.A. Biffi, A.G. Demir, M. Coduri, B. Previtali and A. Tuissi, Laves Phases in Selective Laser Melted TiCr1.78 Alloys for Hydrogen Storage, Mater. Lett., 2018, 226, p 71-74. https://doi.org/10.1016/j.ma tlet.2018.05.028

21. H. Attar, M. Bönisch, M. Calin, L.C. Zhang, S. Scudino and J. Eckert, Selective Laser Melting of in Situ Titanium-Titanium Boride Composites: Processing, Microstructure and Mechanical Properties, Acta Mater., 2014, 76, p 13-22. https://doi.org/10.1016/j.actamat.2014.05. 022

22. C. Bruna-Rosso, A.G. Demir and B. Previtali, Selective laser melting finite element modeling: validation with High-Speed Imaging and lack of Fusion Defects Prediction, Mater. Des., 2018, 156, p 143-153. h ttps://doi.org/10.1016/j.matdes.2018.06.037

23. R.R. Ambriz and D. Jaramillo, Mechanical Behavior of Precipitation Hardened Aluminum Alloys Welds, Light Met. Alloy. Appl., $2014 \mathrm{~h}$ ttps://doi.org/10.5772/58418

24. N.D. Alexopoulos and S.G. Pantelakis, Quality Evaluation of A357 Cast Aluminum Alloy Specimens Subjected to Different Artificial Aging Treatment, Mater. Des., 2004, 25, p 419-430. https://doi.org/10. 1016/j.matdes.2003.11.007

25. J.C. Pereira, E. Gil, L. Solaberrieta, M. San Sebastián, Y. Bilbao and P.P. Rodríguez, Comparison of AlSi7Mg0.6 Alloy Obtained by Selective Laser Melting and Investment Casting Processes: Microstructure and Mechanical Properties in as-built/as-cast and Heat-Treated Conditions, Mater. Sci. Eng. A., 2020, 778, p 139124. https://doi.org/ 10.1016/j.msea.2020.139124

26. H. Rao, S. Giet, K. Yang, X. Wu and C.H.J. Davies, The Influence of Processing Parameters on Aluminium Alloy A357 Manufactured by Selective Laser Melting, Mater. Des., 2016, 109, p 334-346. https://d oi.org/10.1016/j.matdes.2016.07.009

27. T. Hirata, T. Kimura and T. Nakamoto, Effects of Hot Isostatic Pressing and Internal Porosity on the Performance of Selective Laser Melted AlSi10Mg Alloys, Mater. Sci. Eng. A., 2020, 772, p 138713. https://d oi.org/10.1016/j.msea.2019.138713

28. S. Tammas-Williams, P.J. Withers, I. Todd and P.B. Prangnell, The Effectiveness of Hot Isostatic Pressing for Closing Porosity in Titanium Parts Manufactured by Selective Electron Beam Melting, Metall, 
Mater. Trans. A Phys. Metall. Mater. Sci., 2016, 47, p 1939-1946. h ttps://doi.org/10.1007/s11661-016-3429-3

29. N.E. Uzan, R. Shneck, O. Yeheskel and N. Frage, Fatigue of AlSi10Mg Specimens Fabricated by Additive Manufacturing Selective Laser Melting (AM-SLM), Mater. Sci. Eng. A., 2017, 704, p 229-237. h ttps://doi.org/10.1016/j.msea.2017.08.027

30. D. Buchbinder, W. Meiners, N. Pirch, K. Wissenbach and J. Schrage, Investigation on Reducing Distortion by Preheating During Manufac- ture of Aluminum Components Using Selective Laser Melting, J. Laser Appl., 2014, 26, p 012004. https://doi.org/10.2351/1.4828755

Publisher's Note Springer Nature remains neutral with regard to jurisdictional claims in published maps and institutional affiliations. 